\title{
Strain Rate Dependent Ductile-to-Brittle Transition of Graphite Platelet Reinforced Vinyl Ester Nanocomposites
}

\author{
Brahmananda Pramanik and P. Raju Mantena \\ Department of Mechanical Engineering, University of Mississippi, University, MS 38677, USA \\ Correspondence should be addressed to P. Raju Mantena; meprm@olemiss.edu
}

Received 28 November 2013; Accepted 6 January 2014; Published 25 February 2014

Academic Editor: Filippo Berto

Copyright (c) 2014 B. Pramanik and P. R. Mantena. This is an open access article distributed under the Creative Commons Attribution License, which permits unrestricted use, distribution, and reproduction in any medium, provided the original work is properly cited.

\begin{abstract}
In previous research, the fractal dimensions of fractured surfaces of vinyl ester based nanocomposites were estimated applying classical method on 3D digital microscopic images. The fracture energy and fracture toughness were obtained from fractal dimensions. A noteworthy observation, the strain rate dependent ductile-to-brittle transition of vinyl ester based nanocomposites, is reinvestigated in the current study. The candidate materials of $\mathrm{xGnP}$ (exfoliated graphite nanoplatelets) reinforced and with additional CTBN (Carboxyl Terminated Butadiene Nitrile) toughened vinyl ester based nanocomposites that are subjected to both quasi-static and high strain rate indirect tensile load using the traditional Brazilian test method. High-strain rate indirect tensile testing is performed with a modified Split-Hopkinson Pressure Bar (SHPB). Pristine vinyl ester shows ductile deformation under quasi-static loading and brittle failure when subjected to high-strain rate loading. This observation reconfirms the previous research findings on strain rate dependent ductile-to-brittle transition of this material system. Investigation of both quasi-static and dynamic indirect tensile test responses show the strain rate effect on the tensile strength and energy absorbing capacity of the candidate materials. Contribution of nanoreinforcement to the tensile properties is reported in this paper.
\end{abstract}

\section{Introduction}

Vinyl ester based composites are mostly considered in applications such as pipelines and chemical storage tanks. The ester groups in the molecular structure are susceptible to water degradation by hydrolysis. The vinyl ester molecule features fewer ester groups, hence, exhibits better resistance to water and to some chemicals $[1,2]$. The reactive sites in vinyl ester resin are positioned only at the ends of the molecule and hence it helps in improving the length of molecular chain. This long-chain molecular structure maskes vinyl ester resin somewhat tough and resilient. Hence, this candidate material is being considered in ship superstructures which may be subjected to shock waves, impact, and high-strain rate loading.

Characterizing material strength and energy absorption response of materials at higher strain rates has gained increasing attention from multiple researchers. Several attempts $[1,3-10]$ have focused on improving the mechanical properties of vinyl ester composites by providing reinforcement. Graphite nanoplatelet reinforcement and toughening with
CTBN liquid-rubber agent are recently being considered for this composite system. In previous research [11], the authors focused on the roughness of fractured surface. Fractal dimensionality of the fractured failure surface was quantified for predicting the fracture energy and toughness of vinyl ester based nanocomposites. The authors observed [11-15] that the candidate composite systems are high in stiffness, but low in strength, and fail in a brittle fashion. It is observed that the failure of high stiffness and low strength materials is initiated by tensile stress concentrations. Hence, the investigation of the dynamic response of such materials under high-strain rate tensile loading requires serious consideration.

In this paper, previous research on investigation of fractured surface of the candidate materials [11] is revisited and discussed with respect to the strain-rate dependent ductileto-brittle transition. Indirect tensile characterization of the high stiffness low strength graphite platelet reinforced vinyl ester nanocomposites has been performed in the current study. The strength and energy absorption capacity of the candidate materials in both quasi-static and high-strain rate testing are reported. The focus of this research is to 


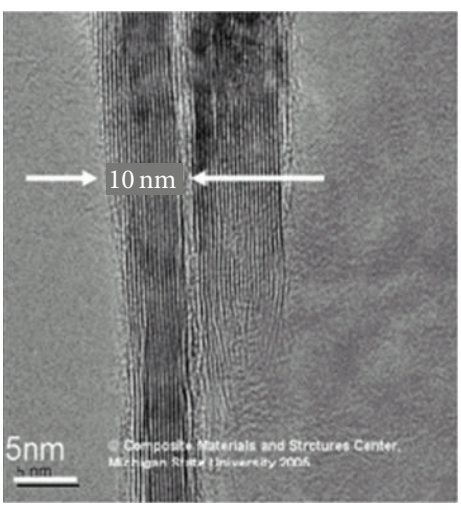

(a)

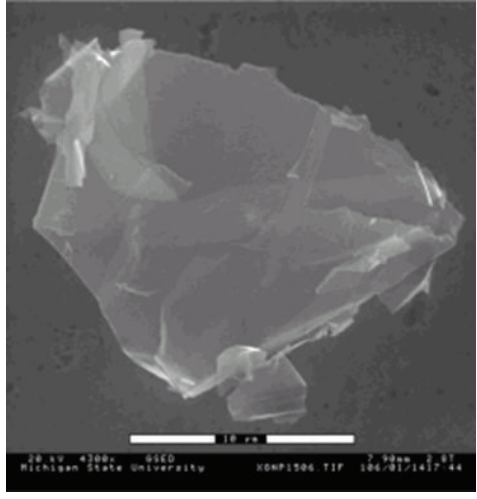

(b)

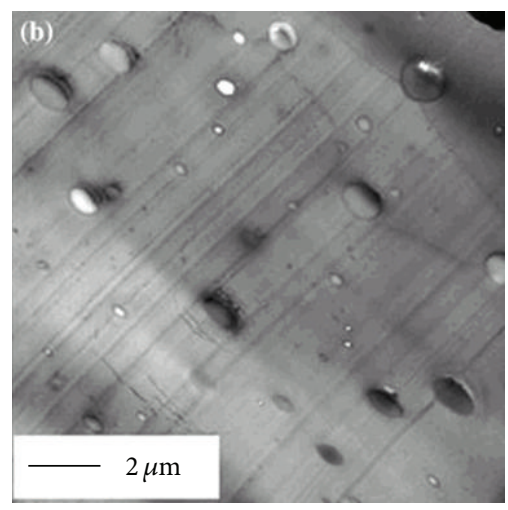

(c)

Figure 1: Typical SEM and TEM morphology of nanoparticle dispersion. (a) Edge view of xGnP flake [8], (b) lateral view of xGnP flake [8], and (c) globular CTBN particles [10].

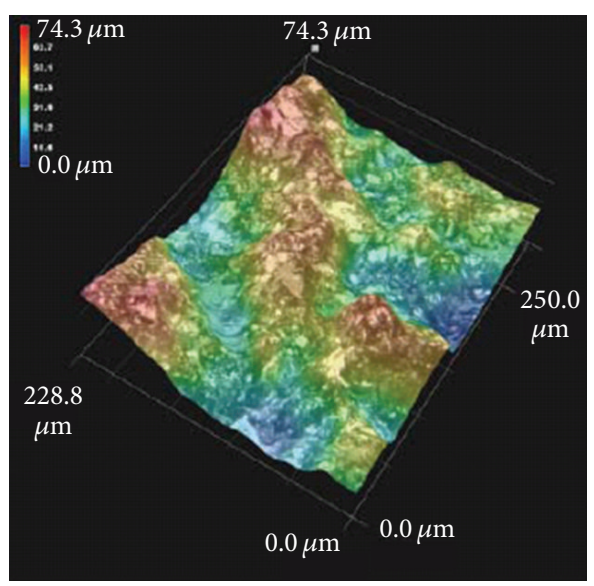

(a)

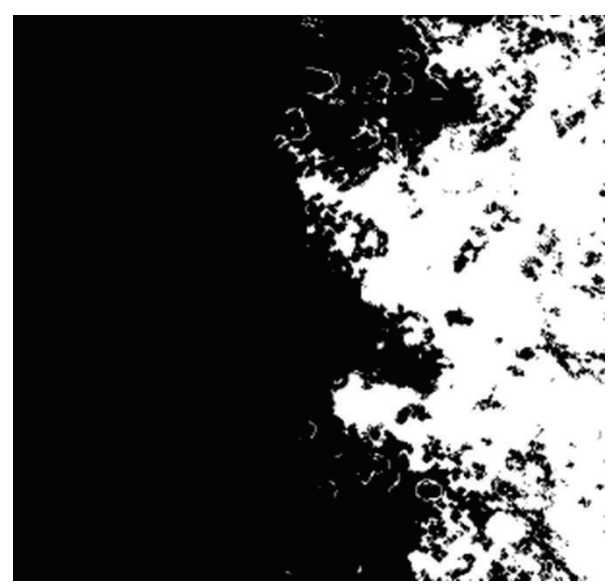

(b)

FiguRE 2: (a) 3D image of typical fractured surface at 1000 times magnification and (b) closed-contour at $10 \mu \mathrm{m}$ depth [11].

demonstrate the indirect tensile strain rate effect on specimen failure mechanism and the contribution of reinforcing and toughening inclusions on improving mechanical properties. This investigation compares the indirect tensile high-strain rate brittle fracture with quasi-static ductile response.

\section{Materials and Methods}

2.1. Materials. Five different Derakane 510A-40 vinyl ester thermoset nanocomposite panels [2] are considered for the dynamic indirect tensile characterization. The brominated bisphenol-A based vinyl ester consists of 38 weight\% styrene, added to Butanone peroxide, N, N-Dimethylaniline, Cobalt Naphthenate, and 2-4-Pentanedione additives to impart maximum fire retardance, chemical resistance, and toughness. Pure brominated vinyl ester polymer (VE) is reinforced with 1.25 weight $\%$ and 2.5 weight $\%$ exfoliated graphite nanoplateletes $(1.25 \mathrm{xGnP}+\mathrm{VE}$ and $2.5 \mathrm{xGnP}+\mathrm{VE}$, resp. $)$ in two different batches. One of the reinforced nanocomposite batches was toughened with 10 weight $\%$ almost unreactive liquid carboxyl terminated butadiene nitrile (CTBN) rubber $(1.25 x G n P+C T B N+V E$ and $2.5 x G n P+C T B N+V E)$.
2.2. Material Fabrication. The nanoparticles are exfoliated and homogeneously dispersed in polymer matrix by applying sonication technique. The homogeneous exfoliation and dispersion is performed in 1 gal container for 4 hours, followed by 4 passes through a flow cell connected to a $100 \mathrm{~W}$ sonicator. The resin solution was mixed for 2 min with FlackTek speed mixer at $3000 \mathrm{rpm}$. The solution of vinyl ester resin with nanoreinforcement and toughening agent is poured into a mold, kept at room temperature for 30 minutes, and then postcured at $80^{\circ} \mathrm{C}$ for 3 hours [8]. Typical SEM and TEM morphology of the candidate materials are shown in Figure 1.

\subsection{Fracture Energy and Toughness from Fractal Dimension} of Fractured Surface. The failed specimens subjected to low velocity impact [15] and quasi-static direct tensile [12] loading were considered in this study. The posttest specimens were as carefully transferred to the observation platform as no further damage may occur to the fractured surface. 3D digital microscopic image (Figure 2(a)) of fractured surface [11] was captured at 1000 times magnification. The contours of the 3D image (Figure 2(b)) at $10 \mu \mathrm{m}$ incremental depths were 


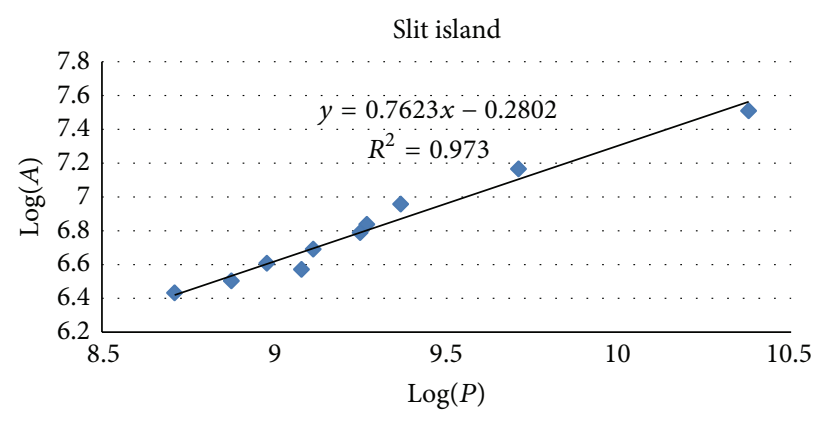

FIGURE 3: Determination of surface fractal dimension from the slope of the regression line on scatter-plot of logarithmic area versus perimeter [11].

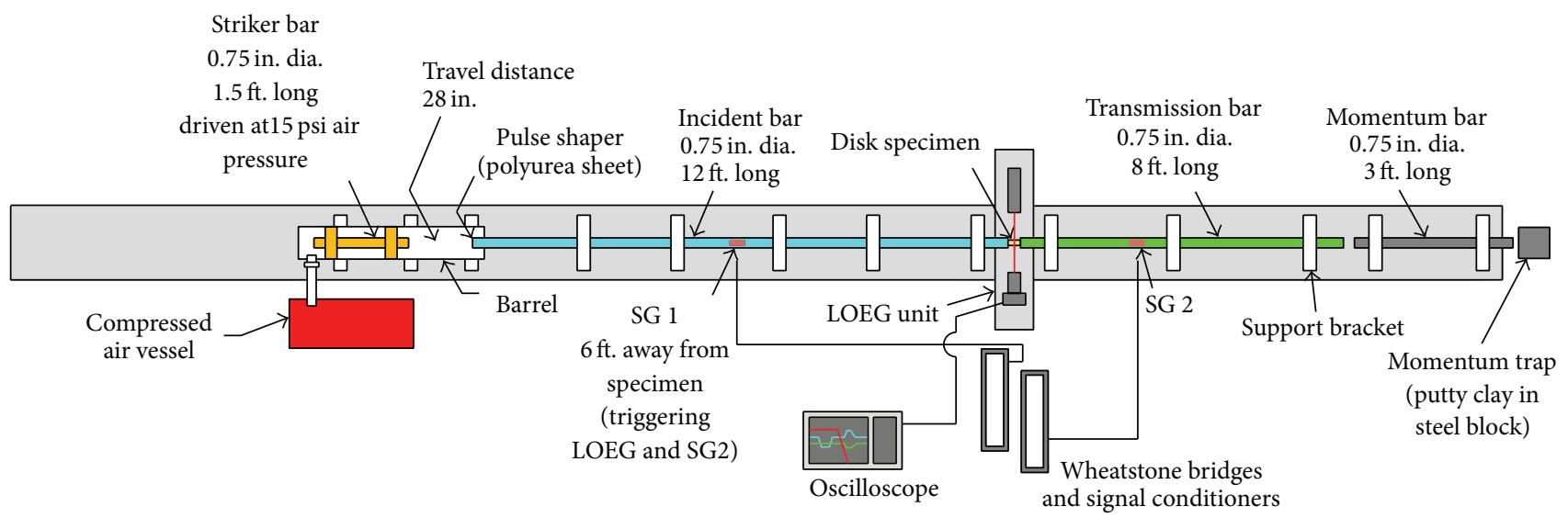

FIGURE 4: SHPB setup for indirect tensile tests including Laser Occluding Expansion Gage (LOEG) system.

extracted using 3D Profile Measurement Software, VHX$\mathrm{H} 2 \mathrm{MK}$. The area and perimeter of the respective closedcontours were estimated using MATLAB functions. The fractal surface dimensionality is obtained from the slope of the regression line on logarithmic area versus perimeter scatterplot (Figure 3). The fracture energy $\left(J_{I C}\right)$ was estimated using equation $J_{I C}=\pi S_{Y}{ }^{2} L^{(D s-2)} / E$, where $S_{Y}$ is yield strength, $L$ is scale of observation, $D s$ is surface fractal dimension, and $E$ is Young's modulus. The fracture toughness $\left(K_{I C}\right)$ was obtained using equation $K_{I C}=\left(J_{I C} \cdot E\right)^{0.5}$.

2.4. High-Strain Rate Indirect Tensile Testing. The molded nanocomposite panels are machined into disk specimens with a diameter of $12.7 \mathrm{~mm}$ using carbide tipped tool in $\mathrm{CNC}$ machine. Traditional split-Hopkinson Pressure Bar (SHPB) apparatus is modified [18] to adapt conventional Brazilian test method (Figure 4) for obtaining high-strain rate indirect tensile response. The tests are performed approximately at $1000 / \mathrm{s}$ strain rate. The disk specimen is held diametrically (Figure 5) by concave end fixtures in between incident bar and transmission bar. The specimen is impacted along the loading axis. The applied compressive forces on the opposite ends $\left(F_{1}\right.$ and $\left.F_{2}\right)$ of the specimen are obtained from SHPB response. The indirect tensile stress experienced by the specimen in transverse direction is obtained using the equation $\left(F_{1}+F_{2}\right) /(\pi D b)$, where $D$ is diameter and $b$ is thickness of the specimen. The indirect tensile strain is obtained using Laser Occluding Expansion Gage (LOEG) unit. It detects the tensile strain developed along transverse diameter. The strength of the material is obtained from the maximum stress before failure and the area under the stress $(\sigma)$ versus strain $(\varepsilon)$ curve $E=\int_{0}^{\varepsilon_{u t}} \sigma(\varepsilon) d \varepsilon$ gives the energy (E) absorbing capacity.

Three samples in each candidate material group were selected for evaluation. The average response is reported along with the maximum data-scatter.

2.5. Quasi-Static Indirect Tensile Testing. Quasi-static indirect tensile experiments [18] are conducted on EnduraTec, a pneumatically driven materials test system (Figure 6). An interface load cell is used to measure the axial load. The disk specimen is mounted diametrically within vertically aligned concave end fixtures. LOEG unit is oriented transversely with respect to the loading axis for measuring the induced transverse tensile strain in disk specimen. The crosshead displacement is set at $0.015 \mathrm{~mm} / \mathrm{s}$ which deforms the specimen approximately at $0.0001 / \mathrm{s}$ strain rate. 


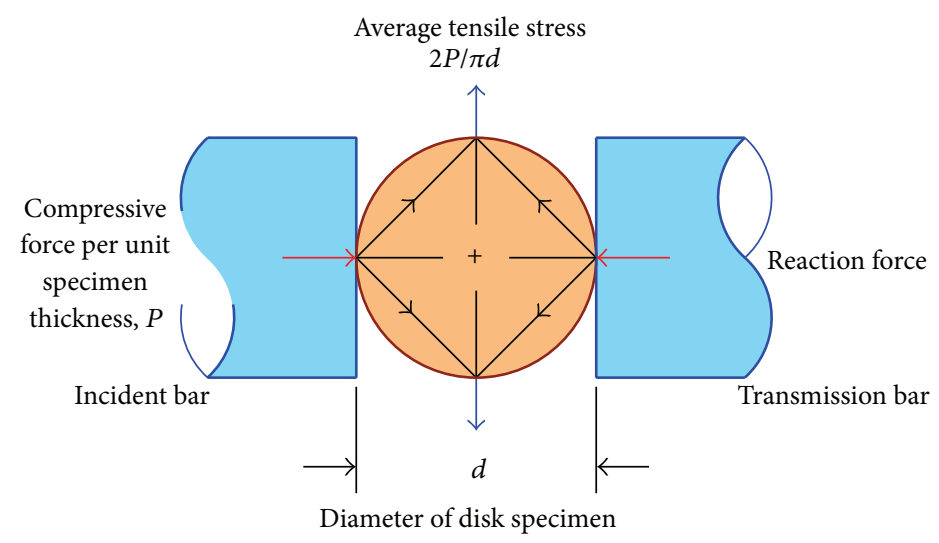

FIGURE 5: Induced tensile stress in circular disk specimen along transverse direction due to applied compressive loading.

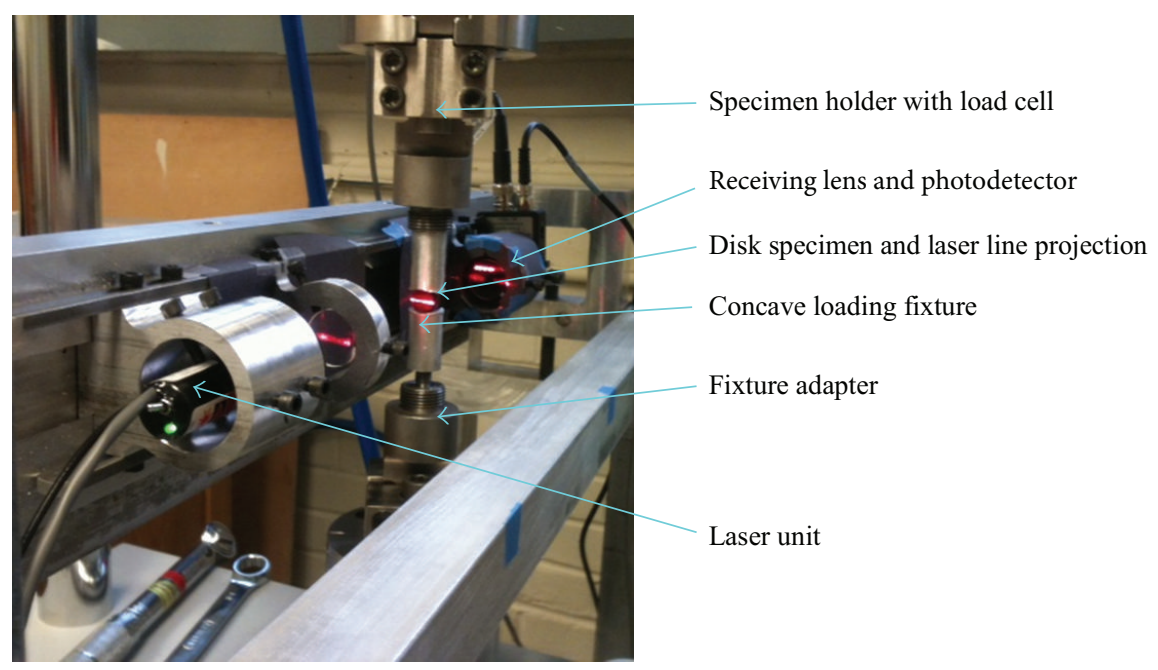

FIGURE 6: Quasi-static indirect tensile test setup with LOEG.

\section{Results and Discussion}

3.1. Quasi-Static Indirect Tensile Response. The quasi-static indirect tensile response of pure vinyl ester specimens (Figure $7(\mathrm{a})$ ) showed ductile deformation response beyond the load cell limit $(10 \mathrm{kN})$. Hence, the conventional Brazilian disk test method, which is appropriate for brittle materials, could not capture the true behavior of pure vinyl ester under quasi-static loading due to its ductility. However, addition of $\mathrm{xGnP}$ and CTBN makes the vinyl ester polymer more brittle (Figure 7(b)) and thus suitable for this indirect experimental method.

The quasi-static indirect tensile stress-strain history for pure vinyl ester, $\mathrm{xGnP}$ reinforced, and CTBN toughened samples are shown in Figures 8(a)(i) and 8(b)(i). As mentioned earlier, stress-strain plots for only the pure vinyl ester specimens have been terminated due to load cell capacity before specimen failure occurs, whereas reinforced samples failed within the load cell range. It can be observed in Figures $8(\mathrm{a})$ (ii) and 8 (b)(ii) that tensile strength of pure vinyl ester is reduced by the addition of $\mathrm{xGnP}$ reinforcement (Figure $8(\mathrm{a})(\mathrm{ii})$ ) and even with CTBN toughening
(Figure 8(b)(ii)). Energy absorbing capacity (Figures 8(a)(iii) and 8 (b)(iii)) is similarly affected by the addition of $x \mathrm{GnP}$ (Figure 8(a)(iii)). The addition of CTBN did not improve the energy absorbing capacity (Figure 8 (b)(iii)) of pure vinyl ester; however, a marginal enhancement (Figure 8(b)(iii)) can be observed when compared to only $\mathrm{xGnP}$ reinforced (i.e., without CTBN, Figure 8(a)(iii)) nanocomposites.

3.2. High-Strain Rate Indirect Tensile Response. Figure 9 summarizes the indirect tensile high-strain rate response of $\mathrm{xGnP}$ reinforced and with additional CTBN toughened vinyl ester nanocomposites at strain rate of 1000/s from SHPB tests. All the nanoreinforced specimens including pure vinyl ester failed in a brittle manner under dynamic tensile loading (Figures 9(a)(i) and 9(b)(i)).

It can be observed that the tensile strength of pure vinyl ester remains unchanged with $\mathrm{xGnP}$ reinforcement (Figure 9(a)(ii)). Addition of CTBN toughening to the 1.25 weight $\% \mathrm{xGnP}$ reinforced nanocomposites showed a marginal improvement (Figure 9(b)(ii)). The energy absorbing capacity of pure vinyl ester is improved with $\mathrm{xGnP}$ 


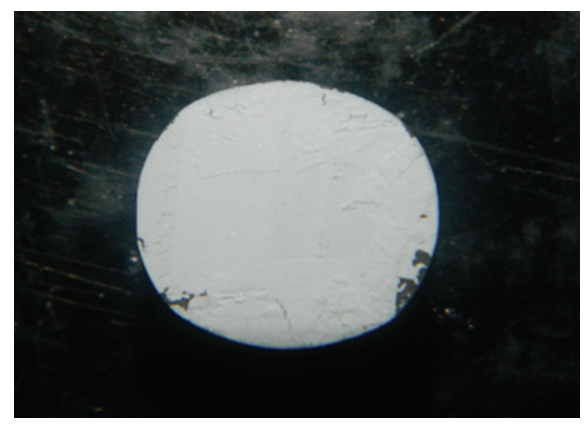

(a)

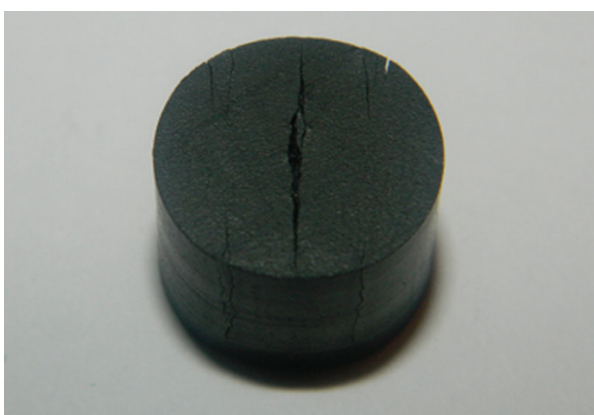

(b)

FIGURE 7: Posttest photographs of (a) pure vinyl ester sample elliptically deformed without diametrical splitting and (b) nanoreinforced composite sample with diametrical splitting.

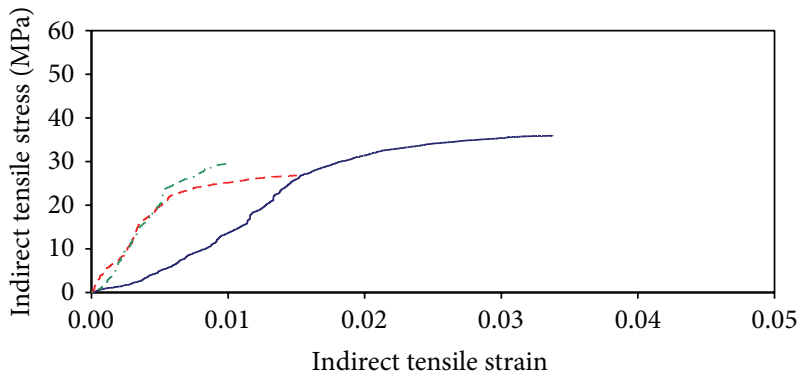

- VE

$--1.25 \mathrm{xGnP}+\mathrm{VE}$

$\cdot-\cdot-2.5 \mathrm{xGnP}+\mathrm{VE}$

(i)

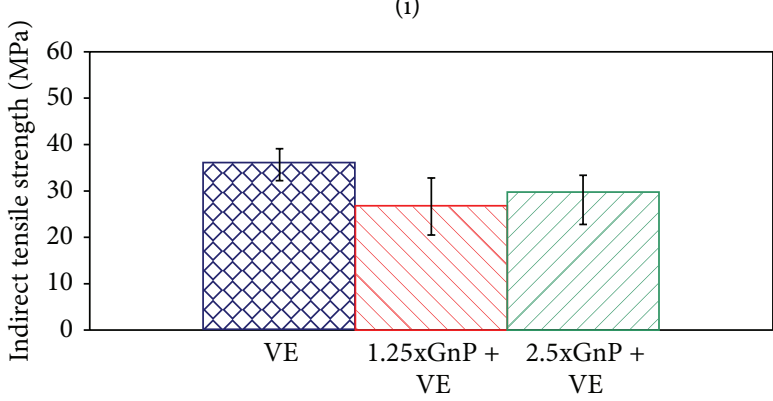

(ii)

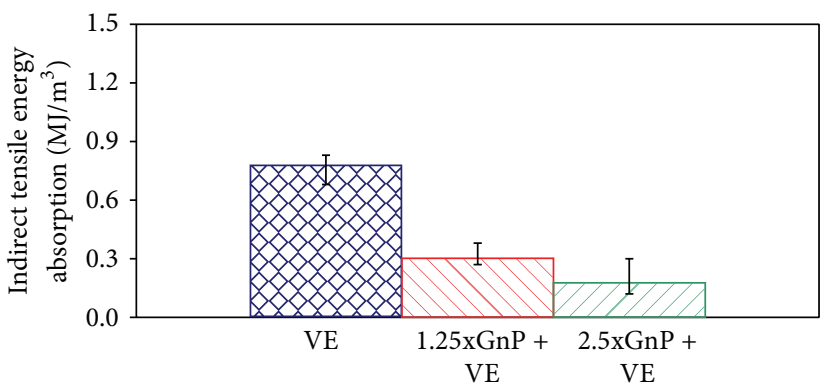

(iii)

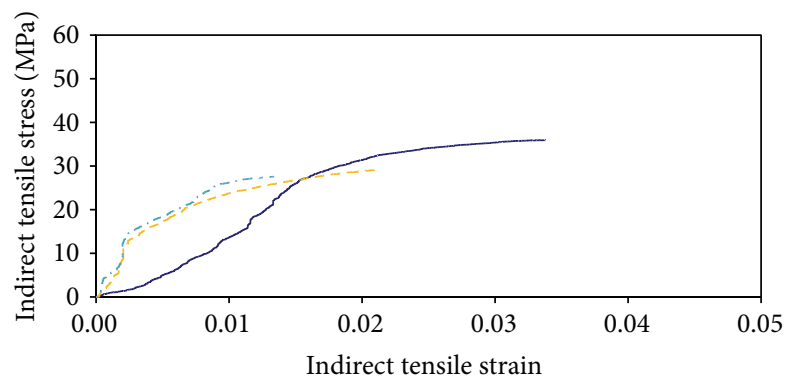

- VE

$--1.25 \mathrm{xGnP}+\mathrm{CTBN}+\mathrm{VE}$

.. $2.5 \mathrm{xGnP}+\mathrm{CTBN}+\mathrm{VE}$

(i)

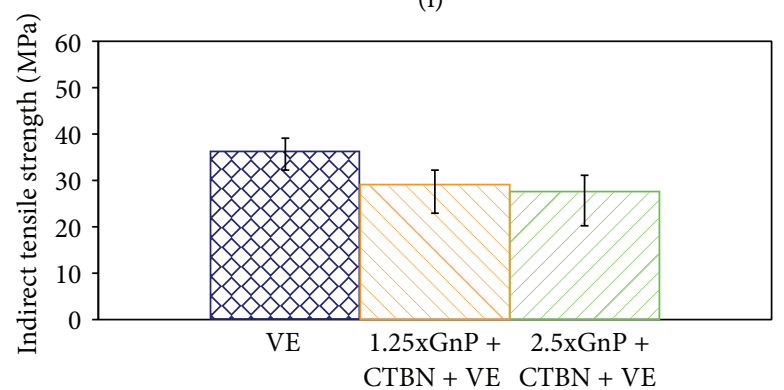

(ii)

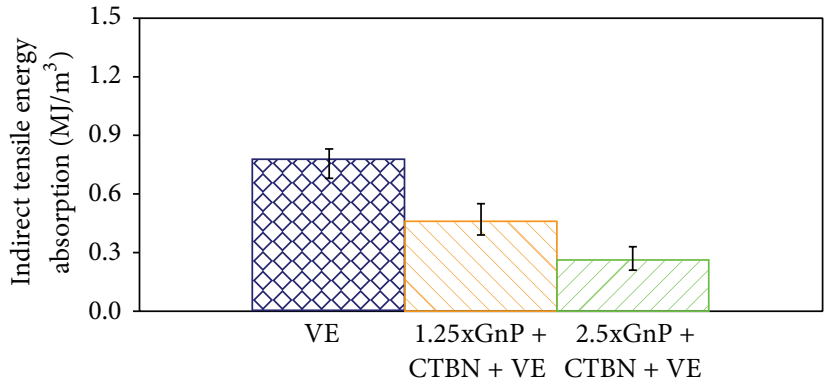

(iii)

(a)

(b)

Figure 8: Quasi-static indirect tensile response. (i) Typical stress versus strain behavior, (ii) strength, and (iii) energy absorbing capacity of (a) graphite platelet reinforced and (b) with additional CTBN toughened vinyl ester nanocomposites (note: pure vinyl ester specimens did not fail within the $10 \mathrm{kN}$ load cell limit of test equipment used for quasi-static testing). 


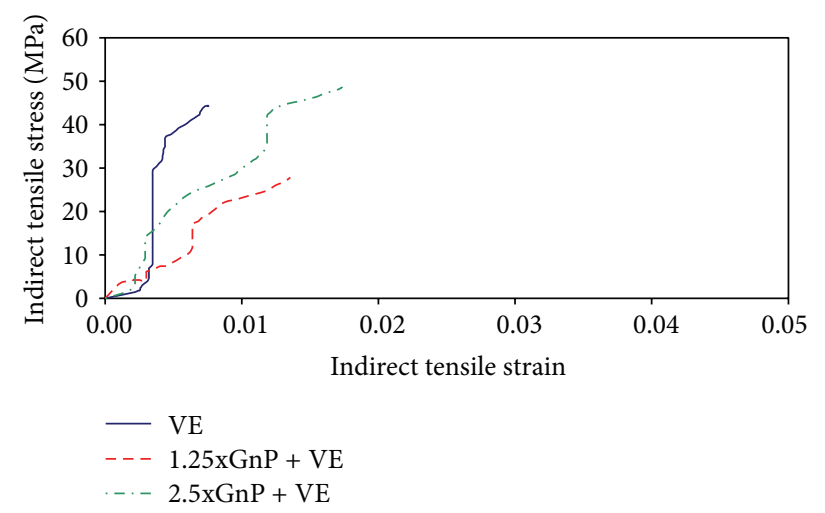

(i)

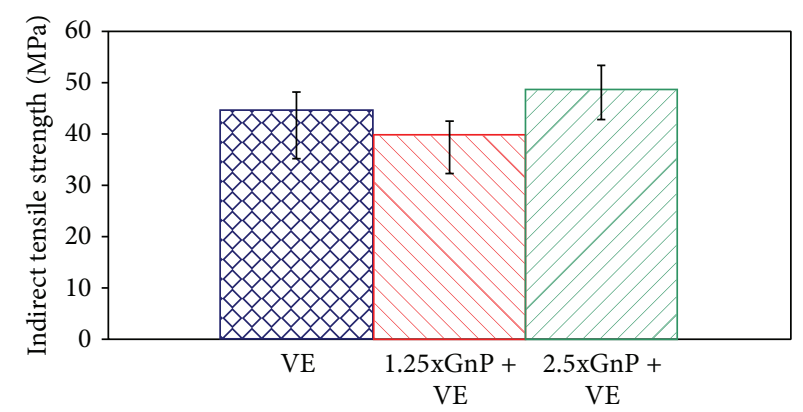

(ii)

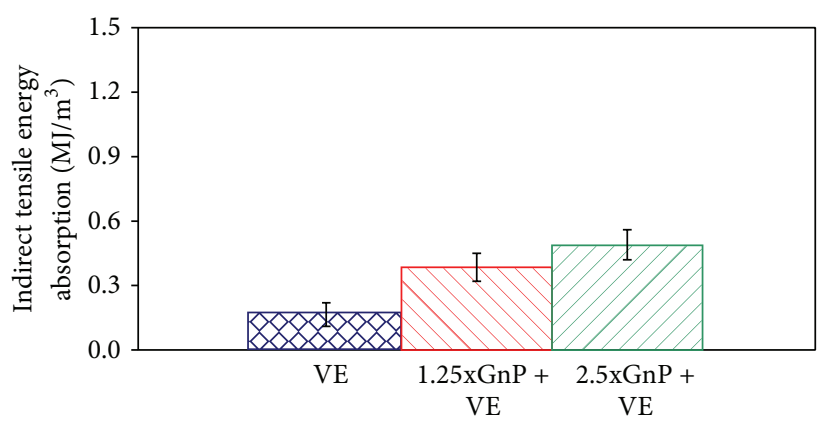

(iii)

(a)

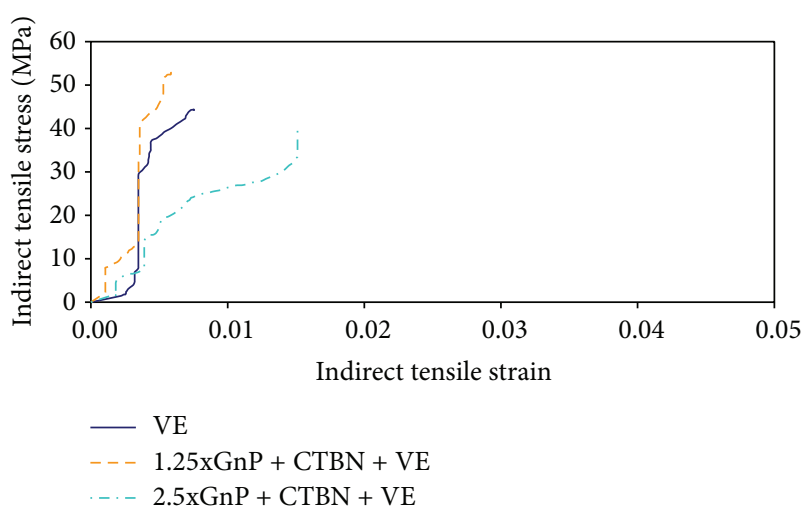

(i)

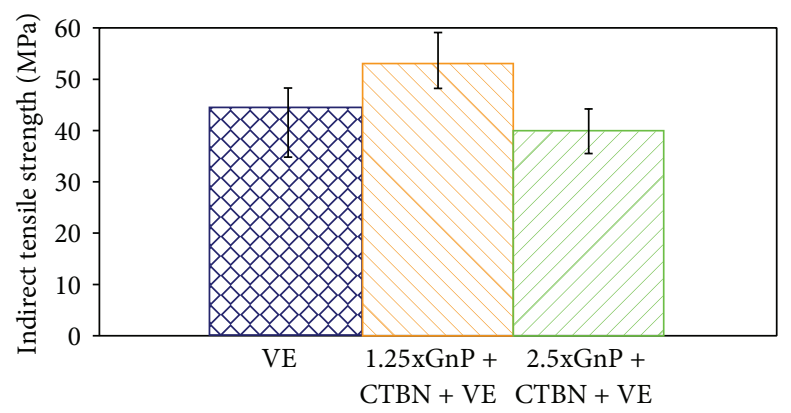

(ii)

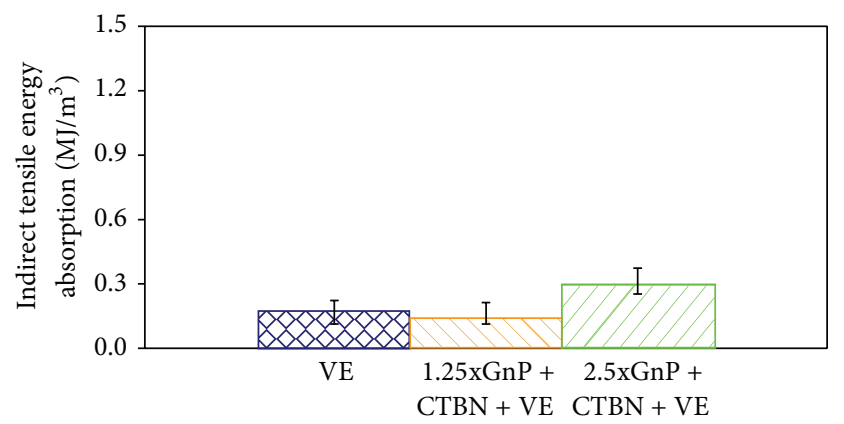

(iii)

(b)

FIGURE 9: High-strain rate indirect tensile response from SHPB tests. (i) Typical stress versus strain behavior, (ii) strength, and (iii) energy absorbing capacity of (a) graphite platelet reinforced and (b) additionally CTBN toughened vinyl ester nanocomposites.

(Figure 9(a)(iii)) reinforcement. However, this improvement is reduced about $50 \%$ by further CTBN toughening to the xGnP reinforced nanocomposites (Figure 9(b)(iii)).

3.3. Strain Rate Effect. Previous research on fractal analysis of fractured surface revealed the strain rate dependent ductileto-brittle transition [11]. The relationship between fractal dimension of the fractured surface and fracture energy of different materials [16, 17] suggests that some composite materials can behave as either ductile or brittle at different strain rates. The authors [11] confirmed that quasi-static direct tensile loading develops ductile fractal surface, whereas low velocity impact creates brittle fractal surface as shown in Figure 10.
In present research, comparative observation of Figures 8 and 9 shows the strain rate dependency of tensile strength and energy absorbing capacity of these candidate materials. As noted earlier, during quasi-static tests pure vinyl ester did not fail within maximum load limit of the load cell used, deforming elliptically in a ductile manner (Figures 7 (a), $8(\mathrm{a})(\mathrm{i})$, and $8(\mathrm{~b})(\mathrm{i}))$. However, it failed in a brittle fashion at much lesser strain (Figures 9(a)(i) and 9(b)(i)) under the high-strain rate SHPB loading. This ductile-to-brittle transition may be due to the significant influence of strain rate effect. These nanocomposites can be considered as thermoviscoelastic under high-strain rate loading in Hopkinson bar experiments, and the time-temperature superposition principle would be applicable for characterizing their response. A 


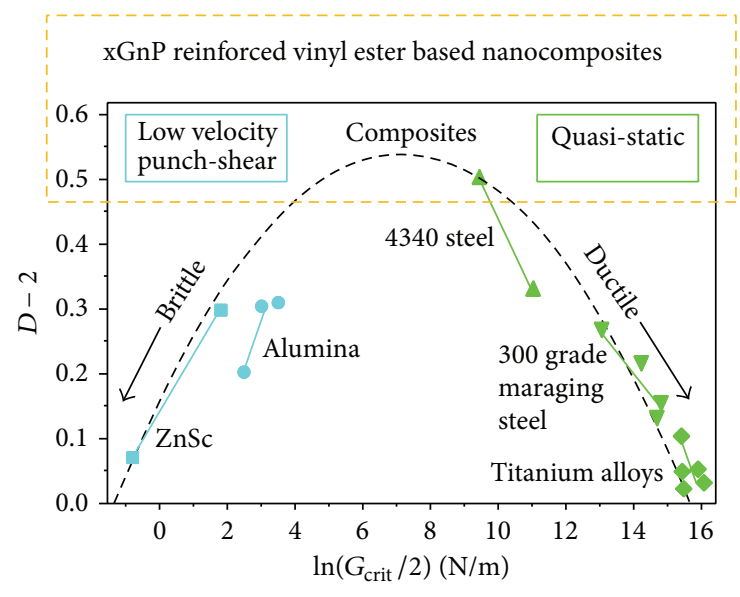

FIGURE 10: Strain rate dependent ductile-to-brittle transition of fracture propagation mechanism investigated by surface fractal analysis $[11,16,17]$.

higher strain rate would correspond to a shorter loading time, equivalent to lower temperatures [19] causing the ductile-tobrittle transition of the specimen. Similar phenomenon has been previously observed by the authors while measuring fractal parameters of the fractured surfaces on the same candidate materials generated [11].

About 25\% increment in tensile strength is observed at high-strain rate loading (Figures 9(a)(ii) and 9(b)(ii)) with respect to the quasi-static response (Figures 8(a)(ii) and 8(b)(ii)). The energy absorption capacity of pure vinyl ester is adversely affected under high-strain rate loading, whereas it is improved with the addition of $\mathrm{xGnP}$ reinforcement (Figures 8(a)(iii) and 9(a)(iii)). However, additional CTBN toughening agent could not contribute towards increasing the energy absorbing capacity (Figures 8(b)(iii) and 9(b)(iii)).

\section{Conclusions}

Surface fractal analysis, in previous research, depicted the ductile or brittle fracture propagation mechanism, depending upon the rate of loading. In the current research, quasi-static and high-strain rate experimental investigations characterize the effect of strain rate and the contribution of $x \mathrm{GnP}$ reinforcement along with CTBN toughening on the indirect tensile properties of vinyl ester based nanocomposites. Tensile strength and energy absorbing capacity of pure vinyl ester are reduced by the addition of $\mathrm{xGnP}$ reinforcement and even with CTBN toughening under quasi-static loading. Addition of CTBN marginally improved the energy absorbing capacity of the only $\mathrm{xGnP}$ reinforced (without CTBN) nanocomposites under quasi-static loading. Tensile strength of pure vinyl ester remains almost the same with the addition of $x G n P$ reinforcement and even with CTBN toughening under highstrain rate loading. Energy absorbing capacity of pure vinyl ester is improved with addition of $\mathrm{xGnP}$ reinforcement under high-strain rate loading. Pure vinyl ester shows ductile-tobrittle transition from quasi-static to high-strain rate loading. Tensile strength observed in quasi-static test is increased at high-strain rate loading for these candidate nanocomposites. The energy absorption capacity of pure vinyl ester is adversely affected under high-strain rate loading.

\section{Conflict of Interests}

The authors declare that there is no conflict of interests regarding the publication of this paper.

\section{Acknowledgments}

Partial support for this research was provided by Office of Naval Research, Solid Mechanics Program (Dr. Yapa D. S. Rajapakse, Program Manager) Grant no. N00014-7-1-1010 and US Army Research Office under the DOD-PIRT subcontract through North Carolina A \& T University Grant no. 300223243A. The vinyl ester nanocomposite panels were manufactured by Dr. Larry Drzal's group at Michigan State University.

\section{References}

[1] K. N. Shivakumar, G. Swaminathan, and M. Sharpe, "Carbon/vinyl ester composites for enhanced performance in marine applications," Journal of Reinforced Plastics and Composites, vol. 25, no. 10, pp. 1101-1116, 2006.

[2] Ashland Inc, "DERAKANE 510A-40 epoxy vinyl ester resin," Technical Datasheet Document 1775V2 F2, 2011, (English).

[3] D. D. L. Chung, "Exfoliation of graphite," Journal of Materials Science, vol. 22, no. 12, pp. 4190-4198, 1987.

[4] M. L. Auad, P. M. Frontini, J. Borrajo, and M. I. Aranguren, "Liquid rubber modified vinyl ester resins: fracture and mechanical behavior," Polymer, vol. 42, no. 8, pp. 3723-3730, 2001.

[5] J. Fröhlich, R. Thomann, and R. Mülhaupt, "Toughened epoxy hybrid nanocomposites containing both an organophilic layered silicate filler and a compatibilized liquid rubber," Macromolecules, vol. 36, no. 19, pp. 7205-7211, 2003.

[6] A. Yasmin and I. M. Daniel, "Mechanical and thermal properties of graphite platelet/epoxy composites," Polymer, vol. 45, no. 24, pp. 8211-8219, 2004.

[7] H. Fukushima and L. T. Drzal, "Graphite nanoplatelets as reinforcement for polymers: structural and electrical properties," in Proceedings of the17th International Conference on American Society for Composites, 2004.

[8] L. T. Drzal and H. Fukushima, "Exfoliated graphite nanoplatelets (xGnP): a carbon nanotube alternative," in Proceedings of the NSTI Nanotechnology Conference and Trade Show, vol. 1, pp. 170-173, Boston, Mass, USA, May 2006.

[9] J. Lu, I. Do, L. T. Drzal, R. M. Worden, and I. Lee, "Nanometal-decorated exfoliated graphite nanoplatelet based glucose biosensors with high sensitivity and fast response," ACS Nano, vol. 2, no. 9, pp. 1825-1832, 2008.

[10] M. Zeng, X. Sun, X. Yao et al., "Free-volume properties and toughening behavior of cyanate ester resin/carboxylrandomized liquid butadiene-acrylonitrile rubber composites," Journal of Materials Science, vol. 44, no. 16, pp. 4270-4278, 2009.

[11] B. Pramanik, T. Tadepalli, and P. R. Mantena, "Surface fractal analysis for estimating the fracture energy absorption of nanoparticle reinforced composites," Materials, vol. 5, no. 5, pp. 922-936, 2012. 
[12] A. Magableh, Viscoelastic and shock response of nanoclay and graphite platelet reinforced vinyl ester nanocomposites, [PhD dissertation], Department of Mechanical Engineering, University of Mississippi, 2010.

[13] P. R. Mantena, A. H. D. Cheng, A. Al-Ostaz, and A. M. Rajendran, "Blast and impact resistant composite structures for navy ships," in Proceedings of Marine Composites and Sandwich Structures, Office of Naval Research, Solid Mechanics Program Review, Adelphi, Md, USA, September 2010.

[14] B. Pramanik and P. R. Mantena, "Viscoelastic response of graphite platelet and CTBN reinforced vinyl ester nanocomposites," Materials Sciences and Applications, vol. 2, no. 11, pp. 16671674, 2011.

[15] B. Pramanik and P. R. Mantena, "Energy absorption of nanoreinforced and sandwich composites in ballistic and lowvelocity punch-shear," Open Journal of Composite Materials, vol. 2, no. 3, pp. 87-96, 2012.

[16] R. E. Williford, "Multifractal fracture," Scripta Metallurgica, vol. 22, no. 11, pp. 1749-1754, 1988.

[17] C. Lu, "Some notes on the study of fractals in fracture," in Proceedings of 5th Australasian Congress on Applied Mechanics (ACAM '07), pp. 234-239, Brisbane, Australia, December 2007.

[18] B. Pramanik, High-strain rate tensile characterization of graphite platelet reinforced vinyl ester nanocomposites using split-hopkinson pressure bar, [PhD dissertation], Department of Mechanical Engineering, The University of Mississippi, 2013.

[19] W. Chen, F. Lu, and M. Cheng, "Tension and compression tests of two polymers under quasi-static and dynamic loading," Polymer Testing, vol. 21, no. 2, pp. 113-121, 2002. 

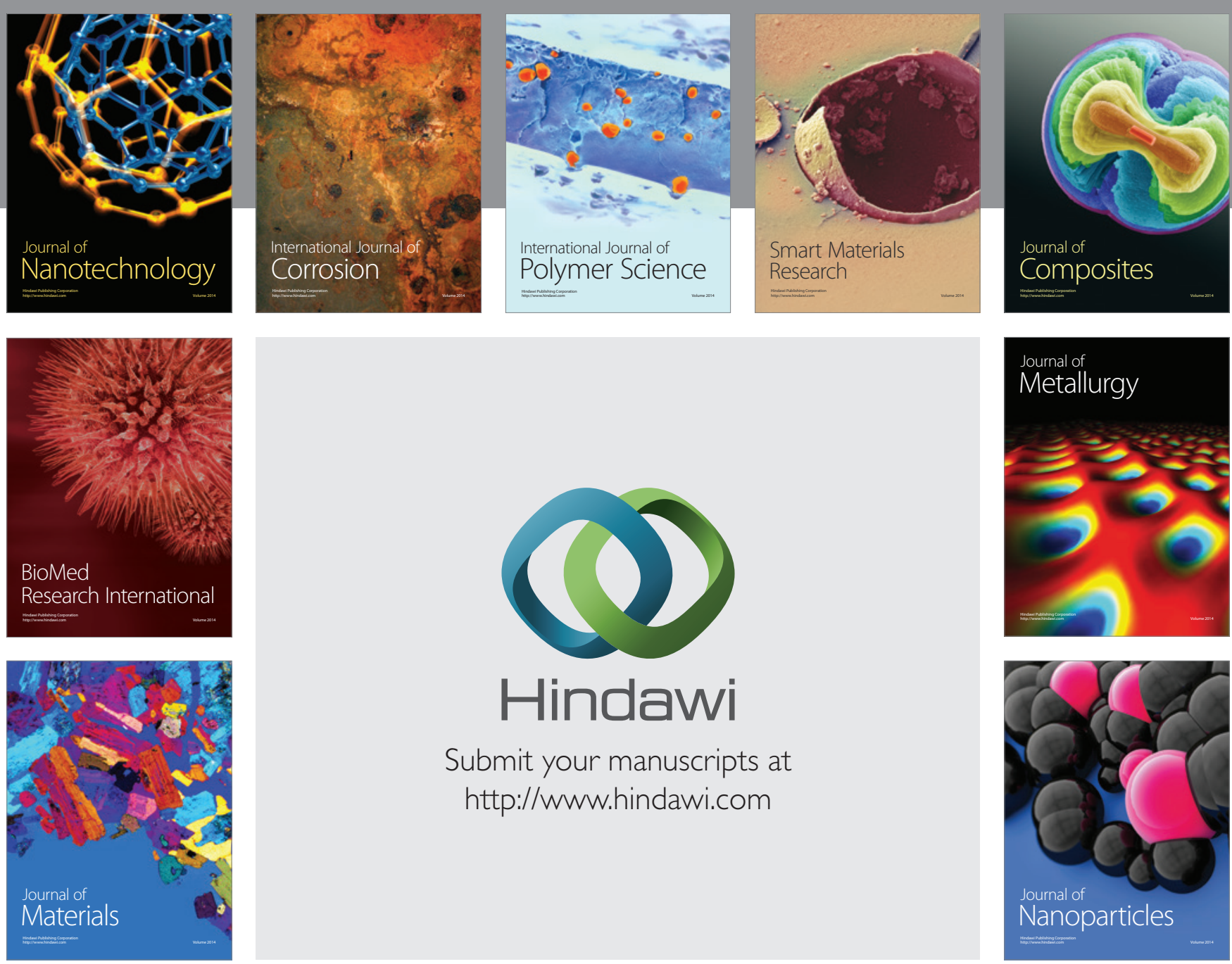

Submit your manuscripts at http://www.hindawi.com
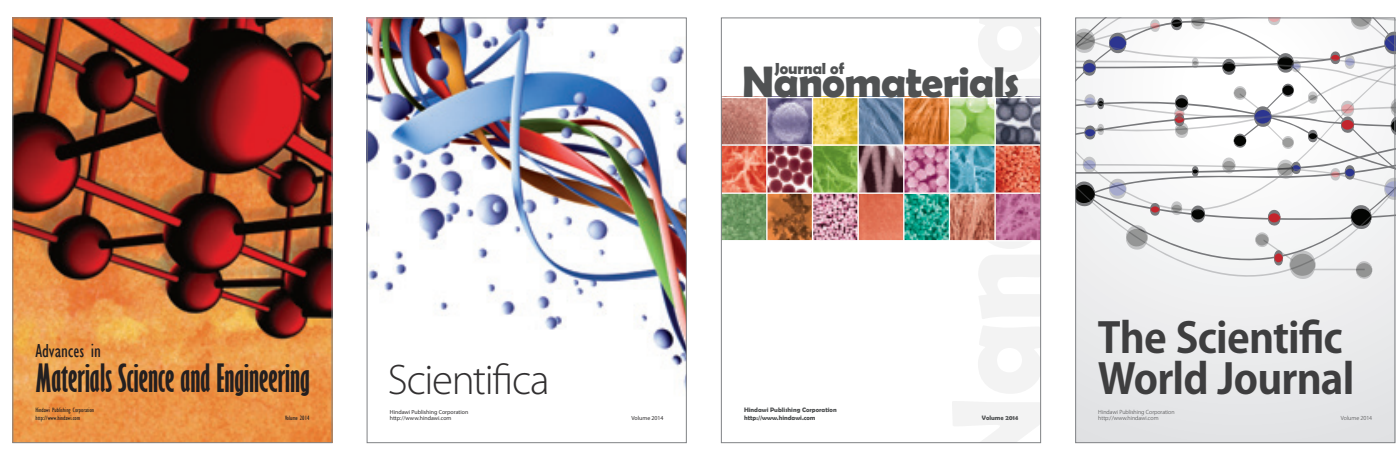

\section{The Scientific World Journal}
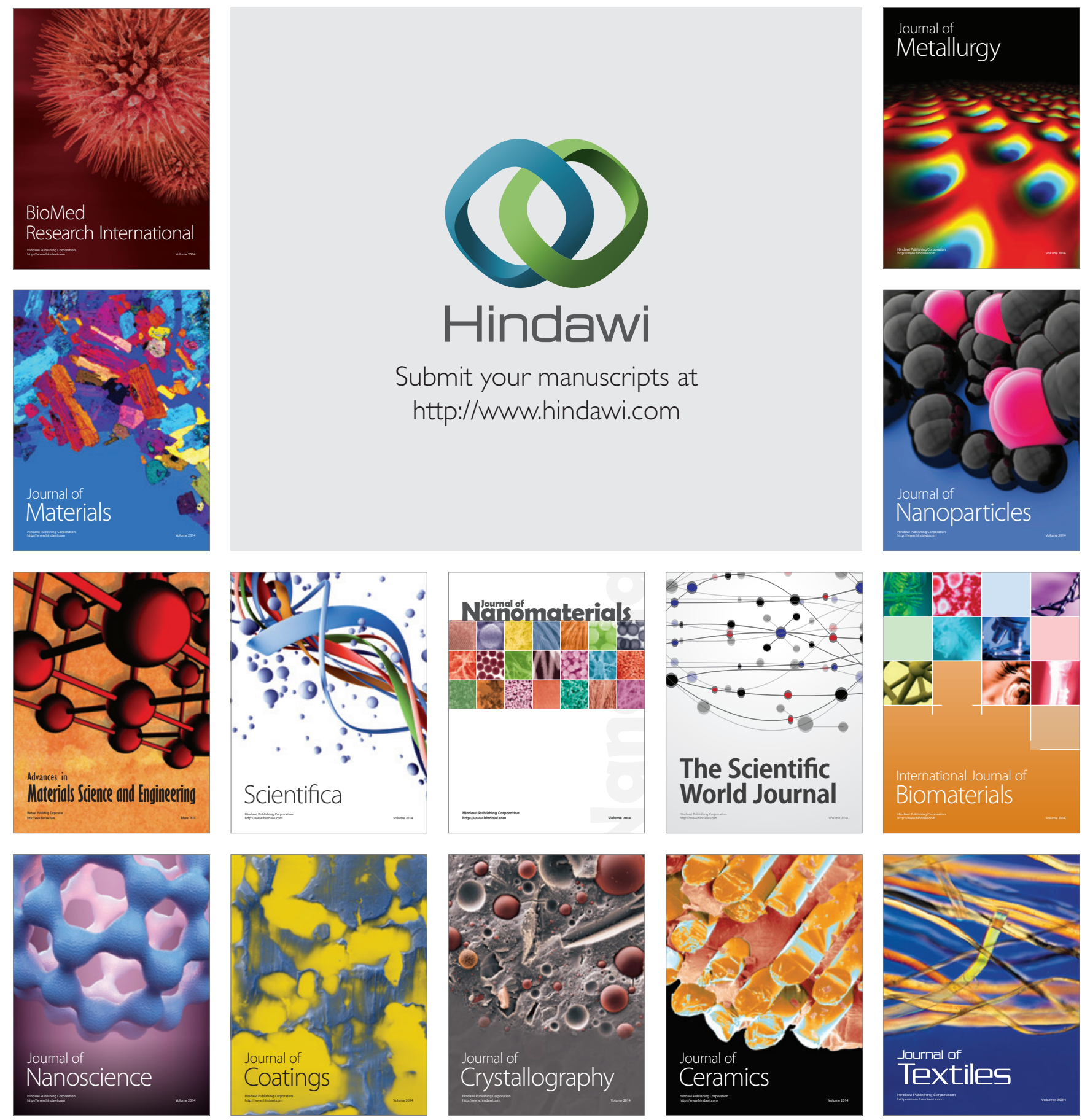